\title{
DESENVOLVIMENTO DE UM SPOT TEST PARA O MONITORAMENTO DA ATIVIDADE DA PEROXIDASE EM UM PROCEDIMENTO DE PURIFICAÇÃO
}

\author{
Ana Eliza Zeraik, Fernanda Sant'Ana de Souza e Orlando Fatibello-Filho* \\ Departamento de Química, Universidade Federal de São Carlos, CP 676,13560-970 São Carlos - SP, Brasil \\ Oldair D. Leite \\ Instituto de Ciências Ambientais e Desenvolvimento Sustentável, Universidade Federal da Bahia, 47805-100 \\ Barreiras - BA, Brasil
}

Recebido em 27/4/07; aceito em 11/1/08; publicado na web em 10/3/08

\begin{abstract}
DEVELOPMENT OF A SPOT TEST FOR PEROXIDASE ACTIVITY MONITORING DURING A PURIFICATION PROCEDURE. In this work we describe both a chromatographic purification procedure and a spot test for the enzyme peroxidase (POD: EC 1.11.1.7). The enzyme was obtained from crude extracts of sweet potatoes and the chromatographic enzyme purification procedure resulted in several fractions. Therefore a simple, fast and economic spot test for monitoring peroxidase during the purification procedure was developed. The spot test is based on the reaction of hydrogen peroxide and guaiacol, which is catalyzed by the presence of peroxidase yielding the colored tetraguaiacol.
\end{abstract}

Keywords: purification procedure; peroxidase; spot test.

\section{INTRODUÇÃO}

O Brasil possui uma grande variedade de frutas e vegetais, sendo que a maioria é de baixo custo e facilmente encontrada em todo o território nacional. Essas frutas e vegetais são fontes inesgotáveis de enzimas que podem ser utilizadas in natura ou como extrato bruto, obtido por procedimentos simples de extração. Dependendo da aplicação analítica, faz-se necessária a purificação da enzima de interesse que, geralmente, é feita empregando-se procedimentos envolvendo várias etapas de pré-purificação, e uma delas consiste no emprego de colunas cromatográficas. Esta etapa do processo de purificação pode resultar em um grande número de frações, tornando assim o monitoramento da atividade enzimática das frações uma etapa lenta e morosa e, em alguns casos, consumindo quantidades significativas de reagentes de custo elevado e de alta toxicidade.

A peroxidase (POD; EC 1.11.1.7) constitui uma classe de enzimas que está extensamente distribuída nos reinos animal e vegetal e pode ser facilmente extraída das células de alguns vegetais. Diversas são as fontes vegetais de peroxidase, como pêssego (Prunus persica), inhame (Alocasia macrorhiza), mandioca (Manihot utilissima), alcachofra (Cynara scolymus L.), batata doce (Ipomoea batatas (L.) Lam.), nabo (Brassica campestre ssp. rapifera), rabanete (Armoracia rusticana), abobrinha (Cucurbita реро) e outras. ${ }^{2}$ Existe um grande interesse por esta enzima, devido as suas múltiplas aplicações em laboratórios de pesquisa, como por exemplo, na construção de biossensores, na indústria de papel e celulose, de alimentos, em análises bioquímicas, entre outras. ${ }^{3}$

O spot test aplica-se a reações químicas sensíveis e seletivas em que a principal característica é a manipulação de pequenos volumes da substância desconhecida e do(s) reagente(s). Caso o resultado da reação entre o(s) reagente(s) e a substância desconhecida seja positivo, o produto formado pode ser identificado a olho nu, seja por modificação de cor ou por formação de precipitado. Este método é aplicável tanto para compostos inorgânicos como

\footnotetext{
*e-mail: bello@dq.ufscar.br
}

orgânicos e, em geral, são procedimentos extremamente simples, rápidos e de baixo custo. ${ }^{4}$

Até hoje não se sabe ao certo quem foi o primeiro a utilizar um spot test para fins analíticos. Segundo Fritz Feigl, ${ }^{4}$ a primeira publicação data de 1834, quando F. Runge usou um papel de filtro contendo imobilizado iodeto de potássio e amido para detectar cloreto livre. Em 1859, Schiff empregou papel de filtro impregnado com carbonato de prata para revelar ácido úrico na urina. Uma gota da amostra produz uma mancha marrom de prata livre. Esta parece ser a mais antiga descrição de um spot test, devido a grande sensibilidade desta reação. Na literatura há vários procedimentos ${ }^{5}$ ${ }^{14}$ utilizando spot test como, por exemplo, determinação de ácido acetilsalicílico, ${ }^{5}$ metildopa,${ }^{6}$ hidroclorotiazida,${ }^{7}$ dipirona ${ }^{8}$ e urotropina ${ }^{9}$ em produtos farmacêuticos. A determinação de potássio em soro sangüíneo, ${ }^{10}$ a detecção de espécies adulterantes em urina, ${ }^{11}$ análise quantitativa de $\mathrm{Fe}(\mathrm{III})$ em aço sintético, ${ }^{12} \mathrm{o}$ controle de nitritos em água ${ }^{13}$ e a determinação do cátion amônio em águas residuárias ${ }^{14}$ foram também descritas na literatura.

Neste trabalho foram desenvolvidos um procedimento de purificação de peroxidase de batata doce e um spot test para determinação qualitativa de peroxidase nas frações eluídas de uma coluna cromatográfica contendo Sephadex G-100. Com o emprego do spot test desenvolvido foi possível selecionar as frações contendo a peroxidase, determinando-se nestas frações a atividade, a concentração de proteína e a atividade específica da enzima peroxidase com grande economia de tempo e de reagentes e, destacadamente, com redução significativa de efluentes de alta toxicidade.

\section{PARTE EXPERIMENTAL}

\section{Instrumentação}

As medidas de absorbância para determinação de proteínas totais e medidas da atividade da peroxidase foram realizadas em um espectrofotômetro com arranjo linear de diodos Hewlett Packard (HP), modelo 8452 A, acoplado a um microcomputador e uma cubeta de quartzo de caminho óptico de $1 \mathrm{~cm}$. 
Para o ajuste do $\mathrm{pH}$ das soluções preparadas, utilizou-se um pHmetro da Orion, modelo EA 940, contendo um eletrodo de vidro combinado Ingold, modelo 10/402/3092.

A coluna cromatográfica foi construída empregando-se um tubo de vidro de $70 \mathrm{~cm}$ de comprimento por $2,5 \mathrm{~cm}$ de diâmetro interno, contendo como fase de separação Sephadex G-100.

Nos procedimentos de purificação, as frações foram recolhidas empregando-se um coletor de frações da Advantec, modelo SF-2120.

\section{Reagentes e soluções}

A solução de guaiacol $15 \mathrm{mmol} \mathrm{L}^{-1}$, utilizada para determinação da atividade da peroxidase, foi preparada a partir da diluição de $0,190 \mathrm{~g}$ deste reagente (Merck; $\mathrm{d}=1,1287 \mathrm{~g} \mathrm{~L}^{-1} ; 98 \% \mathrm{v} / \mathrm{v}$ ) em $100 \mathrm{~mL}$ de água desionizada.

A solução de peróxido de hidrogênio $3,0 \mathrm{mmol} \mathrm{L}^{-1}$, utilizada para determinação da atividade da peroxidase, foi preparada pela diluição de $30 \mu \mathrm{L}$ deste reagente (Reagen, $31 \% \mathrm{~m} / \mathrm{m}$ ) em $100 \mathrm{~mL}$ de água desionizada.

A solução de Azul Brilhante de Coomassie G-250 (Vetec), utilizada na determinação de proteínas totais, foi preparada a partir da solubilização de $50,0 \mathrm{mg}$ deste reagente em $50 \mathrm{~mL}$ de ácido fosfórico (Synth) e posterior diluição desta solução em $500 \mathrm{~mL}$ de água desionizada.

A solução tampão fosfato $0,1 \mathrm{~mol} \mathrm{~L}^{-1}(\mathrm{pH}$ 6,5), empregada na determinação da atividade enzimática, foi preparada dissolvendose $1,7812 \mathrm{~g}$ de $\mathrm{Na}_{2} \mathrm{HPO}_{4}$ e 3,1761g de $\mathrm{KH}_{2} \mathrm{PO}_{4}$ em $500 \mathrm{~mL}$ de água desionizada.

A solução tampão fosfato $10,0 \mathrm{mmol} \mathrm{L}^{-1}(\mathrm{pH} 6,0)$, empregada no procedimento de diálise e fase móvel da coluna cromatográfica, foi preparada dissolvendo-se $0,400 \mathrm{~g}$ de $\mathrm{Na}_{2} \mathrm{HPO}_{4}$ e $1,840 \mathrm{~g}$ de $\mathrm{KH}_{2} \mathrm{PO}_{4}$ em $2000 \mathrm{~mL}$ de água desionizada.

O gel Sephadex G-100 (30 a $80 \mathrm{kD}$ ) empregado na coluna cromatográfica foi preparado da seguinte forma: a $35 \mathrm{~g}$ de Sephadex G-100 foram adicionados $700 \mathrm{~mL}$ de solução tampão fosfato 10,0 mmol L-1 $(\mathrm{pH} 6,0)$. A mistura após homogeneização foi mantida em repouso por $12 \mathrm{~h}$, para estabilização do gel formado. A coluna de vidro (70 cm x 2,5 cm d.i.) foi então preenchida com $500 \mathrm{~mL}$ do gel de Sephadex, sendo utilizado para controlar o fluxo e reter o gel na coluna, algodão e gaze na extremidade inferior da coluna.

A polivinilpirrolidona (PVP) empregada no procedimento de extração, comercialmente conhecida como Polyclar SB 100, foi doada pela empresa ISP Tecnologies Inc. Este polímero foi empregado como agente protetor para remover compostos fenólicos naturais dos extratos enzimáticos, para não serem oxidados pela enzima peroxidase. O bom desempenho deste agente protetor é atribuído à sua baixa solubilidade e à formação de ligação de hidrogênio entre os substratos naturais e o polímero PVP. ${ }^{2} \mathrm{Na}$ etapa de obtenção do extrato bruto (homogenato), após centrifugação, o polímero insolúvel é separado do sobrenadante (homogenato) contendo a peroxidase.

O sulfato de amônio empregado na precipitação das enzimas era procedente da J. T. Baker.

\section{Procedimento experimental}

\section{Obtenção do extrato bruto enzimático}

A fonte enzimática utilizada foi a batata doce, lavada em água corrente, descascada e picada em pequenos pedaços. Uma massa de $25 \mathrm{~g}$ desse tubérculo foi homogeneizada em um liquidificador com $100 \mathrm{~mL}$ de tampão fosfato $0,1 \mathrm{~mol} \mathrm{~L}^{-1}(\mathrm{pH} 6,5)$, contendo $2,5 \mathrm{~g}$ de PVP por 5 min. Em seguida, o homogenato foi filtrado em quatro camadas de gaze e centrifugado a $18000 \mathrm{rpm}$ durante $15 \mathrm{~min}$, a $4{ }^{\circ} \mathrm{C}$.
A solução sobrenadante foi então armazenada em refrigerador a $4{ }^{\circ} \mathrm{C}$ e utilizada como fonte enzimática da peroxidase. ${ }^{3}$

\section{Determinação da atividade da peroxidase}

A atividade da peroxidase presente no extrato bruto foi determinada utilizando-se o guaiacol como substrato. Em uma alíquota de $1,0 \mathrm{~mL}$ de solução tampão fosfato $0,1 \mathrm{~mol} \mathrm{~L}^{-1}(\mathrm{pH} \mathrm{6,5)} \mathrm{foram}$ adicionados 1,0 $\mathrm{mL}$ de guaiacol 15,0 $\mathrm{mmol} \mathrm{L}^{-1}$ e 1,0 $\mathrm{mL}$ de peróxido de hidrogênio $3 \mathrm{mmol} \mathrm{L}^{-1}$. Após a homogeneização dessa solução, adicionaram-se $50 \mu \mathrm{L}$ de extrato enzimático. Depois de $1 \mathrm{~min}$ de reação, a absorbância do tetraguaiacol formado foi medida em 470 nm. Foram realizados controles (brancos) do substrato e da enzima, para verificar se estes não absorviam no mesmo comprimento de onda do produto de oxidação formado (tetraguaiacol).

Para o cálculo da atividade enzimática, $\mathrm{U} \mathrm{mL}^{-1}$, foi empregada a Equação 1.

$\mathrm{U} \mathrm{mL}^{-1}=\frac{A}{\epsilon} \times \frac{1}{V e} \times F D \times \frac{1}{t} \times 1000$

sendo: $\mathrm{U} \mathrm{mL}^{-1}=$ unidade de atividade da peroxidase por $\mathrm{mL} ; \mathrm{A}=$ absorbância; $\epsilon=$ absortividade molar do tetraguaiacol $(26.600 \mathrm{~L}$ $\left.\mathrm{mol}^{-1} \mathrm{~cm}^{-1}\right) ; V e=$ volume da solução de enzima utilizada no ensaio $(\mathrm{mL}) ; \mathrm{t}=$ tempo de reação em min e FD = fator de diluição (diluição do extrato bruto enzimático).

Uma unidade da atividade da peroxidase representa a quantidade de enzima que catalisa a oxidação de $1 \mu \mathrm{mol}$ de guaiacol em $1 \mathrm{~min}^{3}$

A atividade específica (U/mg de proteína) foi calculada pela razão da atividade da enzima $\left(\mathrm{U} \mathrm{mL}^{-1}\right)$ e o teor de proteína total $\left(\mathrm{mg} \mathrm{mL}^{-1}\right)$.

\section{Determinação da concentração de proteínas totais}

As quantificações das proteínas totais nos extratos foram realizadas empregando-se a metodologia descrita por Bradford. ${ }^{15}$ Para a obtenção da curva analítica, $0,1 \mathrm{~mL}$ das soluções padrões de proteína (10 a $100 \mu \mathrm{g} / \mathrm{mL}$ de BSA) foram adicionadas a 4,0 $\mathrm{mL}$ da solução do reagente (Azul Brilhante de Commassie). Após 5 min de reação, a absorbância do complexo formado era medida espectrofotometricamente em $588 \mathrm{~nm}$.

Construída a curva analítica, adicionou-se $0,1 \mathrm{~mL}$ do extrato bruto à solução do reagente; a absorbância do complexo formado foi medida também em $588 \mathrm{~nm}$ depois de 5 min de reação, para determinação da concentração de proteína no extrato.

\section{Precipitação das proteínas (pré-concentração)}

Inicialmente foram realizados estudos preliminares da precipitação das proteínas na presença de diferentes concentrações de saturação de sulfato de amônio. A partir destes estudos realizou-se a precipitação das proteínas em $100 \mathrm{~mL}$ da solução de extrato bruto, em duas etapas. Na primeira etapa, ao extrato foram adicionados $24,3 \mathrm{~g}$ de sulfato de amônio, de modo a se obter $40 \%$ de saturação, pois se notou que a partir daí ocorre a formação significativa de um precipitado e, conseqüentemente, uma clarificação da solução de extrato, proveniente da precipitação dos materiais cito-plasmáticos e nucleares e/ou proteínas presentes, já que nesta porcentagem de saturação não há uma diminuição significativa da atividade (apenas $11 \%$ da atividade inicial). Essa solução foi mantida a $4{ }^{\circ} \mathrm{C}$ por $15 \mathrm{~h} .{ }^{16}$

A seguir, o sobrenadante foi separado do precipitado por centrifugação a $5000 \mathrm{rpm}$ durante $5 \mathrm{~min}$. O precipitado foi descartado e ao sobrenadante adicionaram-se mais $36,78 \mathrm{~g}$ de sulfato de amônio ( $85 \%$ de saturação) e a solução foi mantida a $4{ }^{\circ} \mathrm{C}$ por mais $15 \mathrm{~h}$. Novamente, o sobrenadante foi separado do precipitado por centrifugação a $5000 \mathrm{rpm}$ durante $5 \mathrm{~min}$, sendo que nesta etapa o sobrenadante foi descartado e o precipitado (concentrado de proteí- 
nas) foi ressuspendido em $10,0 \mathrm{~mL}$ de uma solução tampão fosfato $5,0 \mathrm{mmol} \mathrm{L}^{-1}$ ( $\mathrm{pH} \mathrm{6,0),} \mathrm{pois} \mathrm{foi} \mathrm{observado} \mathrm{nos} \mathrm{estudos} \mathrm{preliminares}$ que, nas concentrações entre 85 e $90 \%$ de saturação, a atividade da peroxidase no sobrenadante diminuiu cerca de $85 \%$, quando comparada com a atividade inicial da enzima no extrato de referência (extrato bruto), indicando que quase toda a peroxidase foi precipitada.

\section{Diálise}

Após a pré-concentração, a solução do extrato foi acondicionada em uma membrana semipermeável de celofane (polímero derivado da celulose) e o material foi dialisado durante $8 \mathrm{~h}$ contra 200 $\mathrm{mL}$ de uma solução de tampão fosfato $10,0 \mathrm{mmol} \mathrm{L}^{-1}(\mathrm{pH} 6,0)$ a 4 ${ }^{\circ} \mathrm{C}$. A solução tampão fosfato era trocada em intervalos de $1 \mathrm{~h}$, durante um período de $8 \mathrm{~h}$.

\section{Separação cromatográfica por exclusão molecular com Sephadex G-100}

Após a diálise, um volume de 7,0 $\mathrm{mL}$ do extrato concentrado foi aplicado na coluna. A eluição na coluna foi realizada empregandose tampão fosfato $10,0 \mathrm{mmol} \mathrm{L}^{-1}$ (pH 6,0) numa vazão de $15 \mathrm{~mL} \mathrm{~h}^{-1}$. As frações de 5,0 mL foram coletadas em tubos de ensaio, empregando o coletor de frações automatizado. Nestas frações foram monitoradas as concentrações de proteínas por espectrofotometria no comprimento de onda de $280 \mathrm{~nm}$. Porém, antes da medida da atividade da peroxidase nas frações, foi realizado um spot test (análise de toque) a fim de se verificar em quais frações se observava a presença desta enzima.

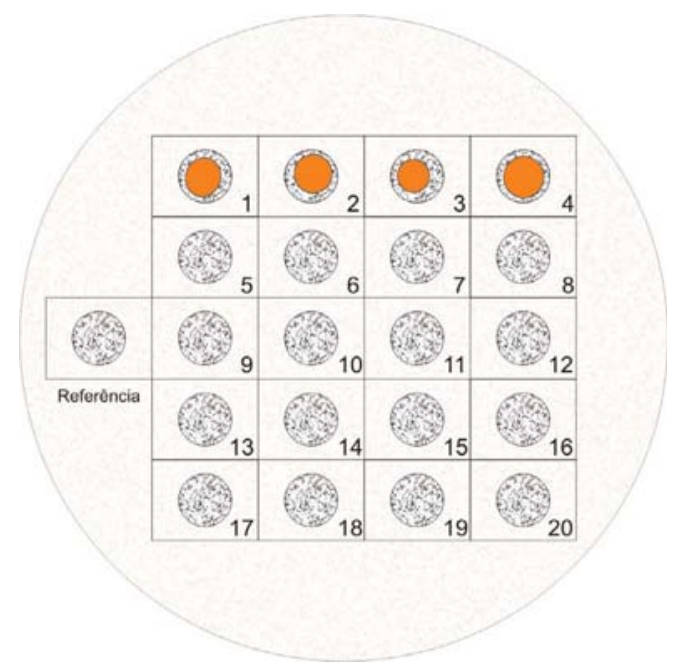

Figura 1. Papel de filtro utilizado para a identificação da peroxidase onde ocorre a reação de oxidação catalítica do guaiacol e peróxido de hidrogênio

Spot test (análise de toque) para a seleção das frações contendo peroxidase

Em um papel de filtro Whatman oํ 1 de $12,5 \mathrm{~cm}$ de diâmetro, foram riscados quadrados de $2 \times 2 \mathrm{~cm}$ com o auxílio de uma caneta de ponta fina. Cada quadrado foi numerado e representava a respectiva fração eluída.

No centro do quadrado respectivo ao controle adicionaram-se, com o auxílio de uma micropipeta, $20,0 \mu \mathrm{L}$ de uma solução tampão fosfato $10,0 \mathrm{mmol} \mathrm{L}^{-1}$ contendo guaicol $15,0 \mathrm{mmol} \mathrm{L}^{-1} \mathrm{e}$ peróxido de hidrogênio $3,0 \mathrm{mmol} \mathrm{L}^{-1}$. Nos outros quadrados repetiu-se este procedimento e, em seguida, adicionaram-se $20,0 \mu \mathrm{L}$ das frações obtidas na etapa de purificação e esperavam-se 3 min para evolução da reação enzimática.

A presença da peroxidase era evidenciada pelo aparecimento de uma coloração alaranjada. A Figura 1 apresenta o papel de filtro quadriculado e numerado, representado as respectivas frações e mais um controle. Este procedimento foi realizado com as 138 frações coletadas da coluna. Posteriormente, nas frações que apontavam a presença da peroxidase, a atividade foi determinada.

$\mathrm{O}$ mesmo procedimento pode ser aplicado, utilizando-se no lugar do papel de filtro uma placa de porcelana (placa de toque) (Figura 2), sendo que cada quadrado do papel de filtro ou cavidade da placa representa uma fração eluída (Figuras 1 e 2).

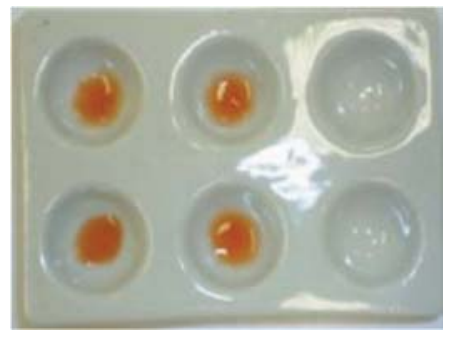

Figura 2. Placa de toque utilizada para identificação de peroxidase nas frações obtidas da coluna cromatográfica

\section{RESULTADOS E DISCUSSÃO}

Obtido o perfil de separação das proteínas, aplicou-se a análise de toque nas frações obtidas para verificar quais apresentavam a presença da atividade da enzima peroxidase. Como discutido na parte experimental, o guaiacol reage com o peróxido de hidrogênio na presença da peroxidase formando o tetraguaiacol de coloração alaranjada (Figuras 1, 2 e 3). Nesta reação, o peróxido de hidrogênio é reduzido e o guaiacol, oxidado, atua como doador de prótons. Desta maneira, somente as frações contendo a peroxidase são analisadas determinando-se a concentração de proteínas totais, atividade total e atividade específica, diminuindo significativamente o número de determinações, o gasto com reagentes, o tempo do analista e, destacadamente, a geração de resíduos.



Figura 3. Esquema da reação onde a enzima peroxidase converte o guaiacol e o peróxido de hidrogênio em tetraguaicol (composto colorido)

Alguns cuidados devem ser tomados quando for empregada esta técnica para análise da peroxidase, uma vez que o desenvolvimento da cor alaranjada indicativa da presença de peroxidase ocorre em um intervalo tempo de 3 a $4 \mathrm{~min}$, sendo que a intensidade de cor diminui gradativamente após esse tempo reacional. Sendo assim, recomenda-se a análise de toque de 15 frações de cada vez para que se possa observar com mais cuidado as mudanças ou não de coloração no papel de filtro quadriculado ou placa de porcelana. A sensibilidade do procedimento espectrofotométrico quando se emprega cubeta de $1 \mathrm{~cm}$ é igual a $26.600 \mathrm{~L} \mathrm{~mol}^{-1} \mathrm{~cm}^{-1}\left(\varepsilon_{470}\right)$, sendo o limite de detecção do spot test (análise de toque) igual a 12,4 $\mu \mathrm{g}$ de guaiacol.

A Figura 4 apresenta atividade da peroxidase $(\mathrm{U} / \mathrm{mL})$ e a concentração das proteínas totais monitoradas pela determinação da absorbância em $280 \mathrm{~nm}$ em função do número de frações. 


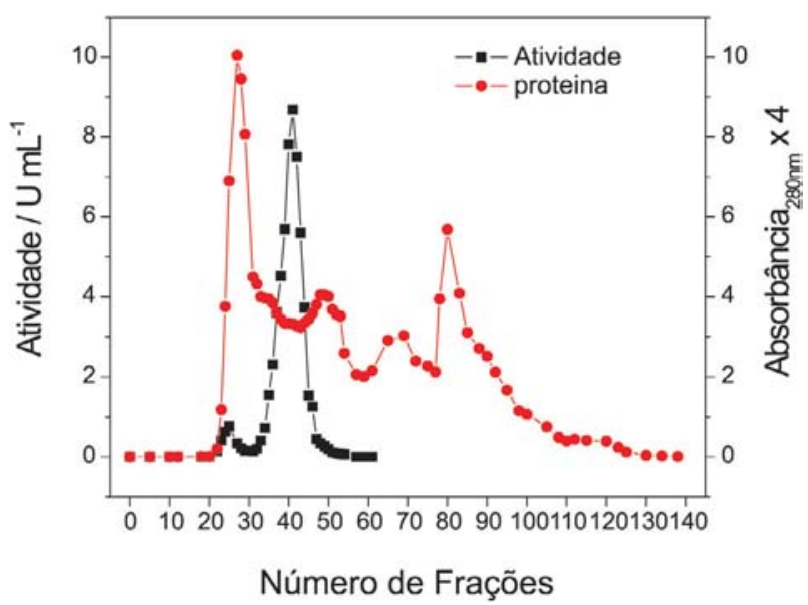

Figura 4. Fracionamento da peroxidase da batata doce em gel Sephadex $G$ 100 (2,5 x 70 cm): Volume das frações de 5,0 mL; monitoramento da peroxidase (U/mL); monitoramento das proteínas (absorbância $280 \mathrm{~nm}$ )

Observa-se na Figura 4 que a peroxidase foi eluída primeiramente entre as frações 21 a 28 e, posteriormente, entre as frações 34 a 50 . Entre as frações 51 a 138 praticamente não se observou a presença da enzima de interesse, sendo essa determinada até a fração 60.

A separação da peroxidase de outras proteínas e/ou substâncias com massas molares distintas, pode ser evidenciada pelo monitoramento das proteínas em $280 \mathrm{~nm}$. A Tabela 1 apresenta os resultados obtidos nos procedimentos de pré-purificação da peroxidase obtida da batata doce.

Tabela 1. Perfil da purificação da enzima peroxidase obtida da batata doce nas diferentes etapas estudadas

\begin{tabular}{|c|c|c|c|c|}
\hline Etapa & $\begin{array}{c}\text { Atividade } \\
\text { total (U) }\end{array}$ & $\begin{array}{l}\text { Proteínas } \\
\text { totais }(\mathrm{mg} / \mathrm{g})\end{array}$ & $\begin{array}{l}\text { Atividade esp. } \\
\text { (U/mg de prot.) }\end{array}$ & $\begin{array}{c}\text { Fator de } \\
\text { purificação }\end{array}$ \\
\hline $\begin{array}{l}\text { Extrato bruto } \\
\text { Após ppt } 85 \%\end{array}$ & 595,49 & 262,96 & 2,26 & 1,0 \\
\hline $\begin{array}{l}\text { Saturação } \\
\left(\mathrm{NH}_{4}\right)_{2} \mathrm{SO}_{4}\end{array}$ & 221,43 & 16,93 & 13,08 & 5,79 \\
\hline $\begin{array}{l}\text { Sephadex } \\
\text { G-100 }\end{array}$ & 55,80 & 2,88 & 19,37 & 8,57 \\
\hline
\end{tabular}

As frações que apresentaram maior atividade da peroxidase, frações 34-50, foram então misturadas, analisadas (Tabela 1) e liofilizadas para serem empregadas como catalisadores em procedimentos analíticos. Ao final do processo de pré-purificação, obteve-se um fator de purificação dessa enzima de 8,57 vezes.

Este procedimento pode ser estendido para outras reações cromogênicas, como por exemplo, na identificação da enzima polifenol oxidase, também presente na batata doce e já identificada por nosso grupo empregando o mesmo procedimento de purificação descrito para a peroxidase.

A presença da polifenol oxidase (PPO) é evidenciada pela coloração amarela, devido à oxidação do fenol pelo oxigênio molecular dissolvido, produzindo 1,2 benzenodiol (catecol) e a oxidação deste produto produzindo a o-quinona. Essas reações são catalisadas pela PPO, ${ }^{17}$ como é mostrado na Figura 5.



Figura 5. Reação de oxidação catalítica do fenol e catecol produzindo a oquinona

\section{CONCLUSÕES}

O desenvolvimento e utilização do spot test no procedimento de purificação enzimática mostrou-se eficaz, possibilitando uma grande economia de reagentes e de tempo do analista. Este procedimento pode ser empregado em laboratórios de pesquisa, que trabalham com purificações de enzimas, ou laboratórios de química analítica que empregam essas enzimas para catalisar alguma reação de interesse analítico. A enzima peroxidase obtida por este procedimento de purificação foi empregada com sucesso na confecção de biossensores para determinação de compostos fenólicos em produtos farmacêuticos ${ }^{2}$ e em amostras ambientais. ${ }^{18}$

\section{AGRADECIMENTOS}

À CAPES, ao CNPq e à FAPESP pelo financiamento parcial deste trabalho e também à FAPESP pelas bolsas de IC de A. E. Zeraik e F. S. de Souza e de doutorado de O. D. Leite.

\section{REFERÊNCIAS}

1. Dekker, R. F. H.; Ling, K. Y.; Barbosa, A. M.; Biotechnol. Lett. 2000, 22 , 105.

2. Fatibello-Filho, O.; Lupetti, K. O.; Vieira, I. C.; Quim. Nova 2003, 26, 39.

3. Lupetti, K. O.; Dissertação de Mestrado, Universidade Federal de São Carlos, Brasil, 2000.

4. Feigl, F.: Anger, V.; Spot tests in organic analysis, Ralph E. Oesoer (Trad.), $7^{\text {th }}$ ed., Elsevier: Amsterdam, 1966.

5. Matias, F. A. A.; Vila, M. M. D.; Tubino, M.; J. Braz. Chem. Soc. 2004, $15,327$.

6. Rubeiro, P. P. P.; Pezza, L.; Pezza, H. R.; J. Braz. Chem. Soc. 2006, 17, 674.

7. Gotardo, M. A.; Pezza, H. R.; Eclet. Quí. 2005, 30, 17.

8. Pezza, L.; Tubino, M.; Melios, C. B.; Pezza, H. R.; Anal. Sci. 2000, 16, 313.

9. Tininis, A. G.; Leandro, A.; Pezza, H. R.; Melios, C. B.; Pezza, L.; Anal. Lett. 2000, 33, 2901.

10. Tubino, M.; Souza, R. L. S.; Hoehr, N. F.; J. Braz. Chem. Soc. 2004, 15, 635.

11. Dasgupta, A.; Chugthai, O.; Hannah, C.; Davis, B.; Wells, A.; Clin. Chim. Acta 2004, 348, 19.

12. Kompany-Zareh, M.; Mansourian, M.; Ravaee, F.; Anal. Chim. Acta 2002, 471, 97.

13. Plata, M. R.; Pérez-Cejuela, N.; Rodríguez, J.; Ríos, A.; Anal. Chim. Acta 2005, 537, 223.

14. Asaoka, S.; Kiso, Y.; Oguchi, T.; Jung, Y.; Yamada, T.; Saito, Y.; Nagai, M.; Talanta 2007, 72, 1100.

15. Bradford, M. M.; Anal. Biochem. 1976, 72, 248.

16. Leite, O. D.; Tese de Doutorado, Universidade Federal de São Carlos, Brasil, 2005.

17. Vieira, I. C.; Fatibello-Filho, O.; Quim. Nova 2002, 25, 455.

18. Fatibello-Filho, O.; Souza, M. G.; Vieira, I. C.; Eclet. Quí. 2002, 27, 51. 